\title{
Medische schaarste en het menselijk tekort
}

Frans Jacobs ${ }^{*}$

De titel van deze tekst suggereert twee heel verschillende probleemgebieden:

macroproblemen rond schaarste in de gezondheidszorg, waarbij het de vraag is hoe de schaarse middelen efficiënt én rechtvaardig ingezet kunnen worden, en microproblemen waarbij die schaarste veelal niet speelt, zoals de vraag hoe een arts een euthanasieverzoek tegemoet dient te treden. Tussen die probleemgebieden bestaan allerlei relaties. Dat het schaarsteprobleem zich op het domein van de medische zorg zo sterk doet voelen, komt immers voort uit het gegeven dat we hier niet te maken hebben met een gewone markt, waar de bekende wetten van vraag en aanbod hun coördinerende functie kunnen vervullen. De patiënt is vaak geen mondige consument, die met een koopkrachtige vraag de aanbieders van medische zorg benadert, zoals dat gaat bij consumenten die een nieuwe tv willen hebben, of liever nog: bij consumenten wier tv kapot is en die hem gerepareerd willen zien. De markt van de cosmetische chirurgie benadert de gewone consumentenmarkt misschien nog het meest, maar die is niet typerend voor het hele domein van de medische zorg. Daar zijn mensen kwetsbaar en afhankelijk, al was het alleen maar doordat er zo'n intieme band bestaat tussen het defect en jezelf, waardoor betrokkenheid, vertrouwen, respect en eerbiediging van de persoonlijke levenssfeer constituerend zijn voor goede zorg. De medische markt is al met al geen gewone markt, en zal dat ook nooit worden. Daarom speelt rond de 'markt van welzijn en geluk' een problematiek die in de titel 'Medische schaarste en het menselijk tekort' al wordt aangeduid.

Prof.dr F.C.L.M. Jacobs is hoogleraar ethiek aan de Universiteit van Amsterdam. 


\section{Medische schaarste}

Onlangs berichtte de krant van een rapport waarin de volgende gegevens voorkomen. Driekwart van de Nederlandse bevolking is tegen het met voorrang behandelen van zieke werknemers, om zo het ziekteverzuim terug te dringen. Als dat wel zou gebeuren, zouden er meerdere gezondheidscircuits ontstaan: collectief betaalde zorg naast privé betaalde zorg, waarbij dat eerste geleidelijk wordt uitgehold, zo vreest men. Driekwart van de bevolking vindt ook dat niet-rokers geen voorrang moeten krijgen boven rokers als er bijvoorbeeld maar één operatietafel is. Is men dan voor een gelijke toegang tot de gezondheidszorg voor iedereen? Dat ook weer niet. Bijna de helft van de bevolking vindt dat een moeder met jonge kinderen eerder geholpen moet worden dan een bejaarde, alleenstaande vrouw. Maar daar staat tegenover dat bijna 90 procent van het publiek voorrangszorg uit den boze acht voor leden van het Koninklijk Huis, ministers, topondernemers en topsporters.

Dit vind ik fascinerende gegevens, die aan het denken zetten. Zit er enig systeem in deze verzameling van opinies? Natuurlijk: wie vindt dat een moeder van jonge kinderen de voorrang verdient boven een bejaarde, hoeft niet dezelfde te zijn als degene die vindt dat de koningin die voorrang niet verdient. Maar laten we aannemen dat het grote publiek één actor is die een beetje probeert na te denken. Hoe vallen al die opinies dan enigszins coherent te maken?

Misschien zo: men stelt economisch belang en publiek belang achter bij menselijk belang. Die bloedjes van kinderen zijn zo zielig: die kunnen hun moeder niet missen, terwijl er niemand is wiens basale welzijn afhangt van een toevallige minister, die trouwens vervangbaar is. Het publiek is dus solidair met degenen wier solidariteitswaarde het grootst is (en niet met degenen wier economische, of politieke, of sportieve waarde het grootst is).

Dit valt gemakkelijk te verenigen met het afwijzen van het 'eigen schuld, dikke bult'. Iemand die zijn leven lang gerookt heeft als een ketter, wordt opeens een zielig hoopje mens als hij een hartkwaal krijgt en mag volgens het beginsel der solidariteit dus niet achtergesteld worden bij een niet-roker als ze beiden een harttransplantatie nodig hebben; ze moeten netjes op volgorde van medische urgentie (of zelfs van binnenkomst) worden behandeld.

Er valt ook een verband te construeren tussen het afwijzen van maatschappelijk belang als positief selectiecriterium en het afwijzen van onmaatschappelijk gedrag als negatief selectiecriterium. Wanneer mensen ziek worden, moeten ze niet op hun maatschappelijk nut of onnut worden beoordeeld. Uitsluitend hun zieligheidsgehalte mag tellen; en zo'n kettingrokende me- 
neer is dan even zielig als een niet-rokende minister of een topondernemer, enzovoort.

Solidariteit van iedereen met iedereen naar rato van ieders zieligheidsgehalte vormt zo de vermoedelijke achtergrond van de opinies van het publiek op het gebied van de gezondheidszorg.

Dit standpunt kan worden ingenomen wanneer mensen ertoe worden uitgenodigd om zich uit te laten over maatschappelijke prioriteiten, zonder dat ze hun persoonlijke positie in de beschouwing betrekken. Je zou misschien zelfs kunnen zeggen: zo'n onpersoonlijk standpunt, dat mensen louter als behoeftige wezens benadert, vormt de kern van een moraal, en wel van een egalitaire moraal. Wanneer het Nederlandse volk gevraagd zou worden om aan te geven wat de moraal van hen vergt, dan zou het wel eens voor den dag kunnen komen met zo'n vorm van egalitaire bejegening.

Dat egalitaire perspectief is natuurlijk zeer respectabel. Toch moet dat perspectief concurreren met een heel ander perspectief. Dat tweede perspectief wil ik op het spoor komen door te verhalen van de beroemde en zelfs ietwat beruchte anarchist William Godwin (1756-1836). U ziet, zegt Godwin in zijn Enquiry concerning political justice (1793), dat de beroemde filosoof/theoloog Fénelon en uw moeder zich in een brandend huis bevinden, en $\mathrm{u}$ kunt slechts een van de twee redden. Wie moet $\mathrm{u}$ te hulp komen? Godwin erkent dat $\mathrm{u}$ waarschijnlijk de neiging voelt opkomen om uw moeder te redden, maar na enig nadenken zult $u$ inzien dat Fénelon een veel waardevoller mens is dan uw moeder, want zijn boeken genezen talloze mensen van dwaling, ondeugd en dus van ongeluk, terwijl uw moeder allen u heeft vertroeteld. $U$ erkent bij nader inzien dat u Fénelon moet redden. De moraal eist van ons dat we zonder onderscheid des persoons te werk gaan: 'What magic is there in the pronoun "my", that should justify us in overturning the decisions of impartial truth?'.

Maar onderscheidt de positie van Godwin tegenover het redden van mensenlevens zich niet juist cruciaal van de positie van het Nederlandse volk tegenover het stellen van medische prioriteiten? Het volk wil precies niet dat maatschappelijk nut daarbij als criterium wordt gebruikt, maar zieligheidsgehalte. Deze objectie valt echter te pareren, door het verhaal anders te vertellen. U ziet dat uw kind en het kind van de buren in het water zijn gevallen en dreigen te verdrinken. Wie moet $u$ te hulp komen? Moet je dan hun respectieve zieligheidsgehalte afwegen? Een onpersoonlijk standpunt als dat van Godwin zou vergen dat we op zoek gaan naar zulk een criterium. Maar velen van ons zouden dat verwerpelijk vinden: een moraal die van ons eist dat we in zo'n geval de voorkeur geven aan een onpersoonlijk standpunt boven een persoonlijke standpunt, zou niet alleen onmenselijk zijn, maar mis- 
schien zelfs immoreel, door haar fanatisme. Daarmee stelt zich een persoonlijk standpunt naast een onpersoonlijk standpunt, en krijgt dat tweede niet vanzelf de voorrang.

$\mathrm{Nu}$ is er in de geschiedenis van de ethiek een theorie uitgedacht die aan het persoonlijke standpunt recht heeft willen doen zonder het onpersoonlijke standpunt op te geven. Dat is het utilisme. En het utilisme is tevens de eerste theorie die een variant heeft bedacht van wat je een morele arbeidsverdeling zou kunnen noemen. Dat laatste komt hierop neer. Als iedereen altijd het onpersoonlijke standpunt zou innemen en mensen zou bejegenen naar rato van hun zieligheidsgehalte, dan zou de zieligheid minder effectief worden bestreden dan wanneer iedereen primair voor zijn eigen kinderen en vrienden zou zorgen, ook wanneer die minder zielig zijn dan die van de buren. Dus dringt zich een soort van morele arbeidsverdeling op: iedereen is primair verantwoordelijkheid voor zijn eigen kinderen, en wanneer iedereen zijn steentje bijdraagt, wordt de zieligheid in de wereld optimaal gereduceerd.

Problematisch aan deze theorie is ten eerste dat mensen tot enige schizofrenie worden gedreven: ze mogen wel van hun kinderen houden, maar niet omdat ze nu eenmaal hun kinderen zijn, maar omdat het maatschappelijk nuttig is dat mensen primair van hun eigen kinderen houden. Problematisch is ten tweede dat stilzwijgend wordt aangenomen dat private vices inderdaad tot public benefits zullen leiden (vergelijk Mandeville's The Fable of the Bees, 1705). Maar is dat zo zeker? Het is waarschijnlijker dat er een samenleving ontstaat met enorme verschillen tussen rijk en arm, tussen mensen die zich een goede gezondheidszorg kunnen veroorloven en mensen die dat in het geheel niet kunnen. Blijkbaar moet er zoiets zijn als een nationale of zelfs internationale regie die erop toeziet dat de gezondheidszorg ten goede komt aan iedereen. Alleen wanneer het egoïsme en het beperkte altruïsme (self-referential altruism) een ondersteuning vormen van het schema der universele hulpverlening, kunnen ze worden toegelaten.

Laten we de utilistische theorie der morele arbeidsverdeling langs deze lijnen amenderen. Mensen mogen gewoon voor hun geliefden zorgen, en ze hoeven niet tegelijk met een scheef oog te bekijken of dat wel in het universele menslievendheidsschema past, als ze erop mogen vertrouwen dat de overheid, door het uitvaardigen van verstandige directieven, zorgt voor de volksgezondheid. In de regel kunnen de mensen dan hun intuïties volgen; alleen in uitzonderingsgevallen moeten ze die utilistisch toetsen.

Is deze aldus geamendeerde utilistische theorie van de morele arbeidsverdeling aanvaardbaar? Zij veronderstelt een opvatting over individuele verant- 
woordelijkheid en over overheidsverantwoordelijkheid die problematisch zijn.

De individuele verantwoordelijkheid is hier tegelijk minimaal en maximaal. Minimaal: mensen mogen niet onbekommerd voor hun eigen belangen en voor de belangen van de hunnen opkomen, maar moeten zich voortdurend afvragen of zich hier geen uitzonderingstoestand voordoet, in welk geval ze zich niet zomaar kunnen beroepen op de bestaande morele arbeidsverdeling. Dat maakt hun verantwoordelijkheid meteen maximaal: het gezichtspunt waaronder ieders handelen wordt beoordeeld, is dat van het maatschappelijke nut.

De utilistische theorie der morele arbeidsverdeling heeft ook een problematische visie op de taken van de overheid. De overheid wordt hier paternalistisch: zij ziet er uitsluitend op toe dat het geluk gemaximaliseerd wordt, waarbij aan de mensen zo min mogelijk eigen beslissingsbevoegdheid wordt toegekend. (Dat paternalisme blijkt fraai uit Sidgwicks vermoeden, geuit in The Methods of Ethics, 1874, dat overheden er goed aan doen om hun utilistische standpunt verborgen te houden en de mensen niet een utilistische moraal bij te brengen, maar bijvoorbeeld een Kantiaanse. Misleiding met goede bedoelingen: dat is bij uitstek paternalisme.) In deze visie komt er aan de taken van de overheid ook nooit een einde; de utilistische verdelingstheorie is onverzadigbaar. Ter verduidelijking: een verdelingstheorie is onverzadigbaar wanneer ieder nieuw item dat zich aandient of geproduceerd wordt, in de verdeling moet worden gebracht. Zo is een radicaal egalitaire inkomenspolitiek onverzadigbaar, omdat zij bij iedere extra verdiende gulden de vraag moet stellen hoe die zo kan worden besteed dat de maatschappelijke gelijkheid wordt bevorderd. Zo'n theorie is tot Sisyphusarbeid gedwongen; denk aan Nozicks voorbeeld van Wilt Chamberlain, dat hij ontwikkelt in zijn Anarchy, State and Utopia (1974). Stel dat een egalitarist erin geslaagd is om het door hem geprefereerde verdelingspatroon te verwerkelijken: iedereen heeft bij voorbeeld evenveel. Allen gaan nu kijken naar Wilt Chamberlain, een beroemd basketbalspeler, en geven hem in ruil daarvoor telkens een dubbeltje. Ze zijn na deze transactie allemaal een dubbeltje armer, terwijl Wilt Chamberlain schatrijk is: een patroon van ongelijke verdeling. Moet je dan opnieuw aan het herverdelen slaan?

Hoe moet het dan? Algemeen gesteld: het onpersoonlijke, perspectief moeten we niet opvatten als een vervanging van het persoonlijke perspectief, maar als een correctie erop. Daarbij wordt het persoonlijke perspectief bij voorbaat als legitiem erkend, en corrigeert het op zijn beurt een tot in het extreme doorgevoerd onpersoonlijk perspectief. Dat mensen van hun eigen kinderen houden en voor hun eigen kinderen willen zorgen is niet iets wat 
als zodanig onder morele verdenking staat: dat is een van de uitgangspunten (topoi, gemeenplaatsen) van iedere aanvaardbare ethiek. Maar dat betekent niet dat mensen bij het zorgen voor hun eigen kinderen de belangen van andere kinderen met voeten mogen treden. Het staat iedereen vrij om zijn eigen kinderen te bevoordelen door uitsluitend aan hen een ijsje te geven, maar wanneer jouw kind ruzie heeft met dat van de buren, moet je niet blind partij kiezen voor je eigen kind, maar proberen te achterhalen wat er mis is gegaan en wie er misschien begonnen is. De bereidheid om enige afstand te nemen van het 'Right or wrong, my child', is een zekere correctie op het zelf-referentiële altruïsme (of alter-referentiële egoïsme), terwijl dat toch niet totaal wordt opgeslokt. De uitwassen ervan worden getemperd.

We zouden nu kunnen zeggen dat de mensheid met vallen en opstaan een moreel leerproces aan het doorlopen is, waarbij we een balans proberen te vinden tussen individuele vrijheid en maatschappelijke verantwoordelijkheid, tussen het persoonlijke perspectief en het onpersoonlijke perspectief, die elkaar corrigeren. Dat is opnieuw een vorm van morele arbeidsverdeling, maar met een typisch verschil tegenover de utilistische arbeidsverdeling. Hier worden immers niet alleen morele taken verdeeld, maar ook morele rechten (in de zin van bevoegdheden of misschien van privileges), bijvoorbeeld het recht om je eigen kinderen te bevoordelen boven die van de buren. Die rechten stellen een grens aan de taken die je hebt, waardoor zulk een theorie niet onverzadigbaar is, niet maximalistisch en niet paternalistisch.

Dit is het precies waarop Thomas Nagel afstuurt, de uitvinder van de term 'morele arbeidsverdeling' (zie zijn Equality and Impartiality, 1991): als op bijvoorbeeld nationale schaal voor iedereen een aanvaardbaar niveau van gezondheidszorg is verzekerd, is het moreel toelaatbaar dat op lokaal niveau diegenen die het kunnen opbrengen, aan zichzelf en de hunnen extra voordelen doen toekomen. 'Partijdigheid' is dus volgens Nagel toelaatbaar binnen een schema van morele arbeidsverdeling waarin 'gelijkheid' voldoende gerealiseerd is.

Hoe kunnen we van hieruit kijken naar de problematiek van de medische selectie? Wat te denken van privé-klinieken waarin koopkrachtige mensen snel geholpen worden, van bedrijvenpoli's die het mogelijk maken om aan wachtlijsten te ontkomen, van zorginstellingen waarin rijke ouderen zich luxueus laten vertroetelen, terwijl anderen zijn aangewezen op de thuiszorg of op een kamer die ze met anderen delen?

Als we overgaan naar een meer 'vraaggerichte' gezondheidszorg in plaats van de huidige grotendeels 'aanbodgerichte', dan zijn zulke verschillen onontkoombaar. Er komen dan ongetwijfeld ook gezondheidszorgondernemingen die zeer winstgevend kunnen zijn en die ook met het oog daarop in 
het leven worden geroepen. Ik ben benieuwd hoe het Nederlandse publiek in een volgende onderzoek daarop zal reageren. Zullen de solidariteitsreflexen waarop ik in het begin wees, dan weer de kop opsteken? Zal het Nederlandse volk een vraaggerichte gezondheidszorg interpreteren als een teken van een afname van maatschappelijke solidariteit en van een toename van morele verloedering? Zijn we ermee bezig het morele leerproces van Nederland terug te draaien? Ik denk dat we ons allemaal de ingewikkelde logica eigen moeten maken van die morele arbeidsverdeling. Daarin bestaat ruimte voor 'maatschappelijke solidariteit': er zullen politieke beslissingen genomen moeten worden over de vraag welke zorg voor iedereen beschikbaar dient te zijn. Maar vanuit de gedachte van de morele arbeidsverdeling ontstaat er ook enige ruimte voor het legitiem najagen van eigenbelang en groepsbelang. Wie het 'egoïsme' trouwens geheel van de morele agenda wil verwijderen, lokt uit dat het op een verkapte manier en ongecontroleerd toch weer zijn kop opsteekt.

\section{Menselijk tekort}

Martha Nussbaum vertelt in haar artikel 'Transcending Humanity' (verschenen in Love's Knowledge, 1990) het verhaal van Odysseus en Calypso uit de Odyssee. Odysseus, die al vele jaren op het eiland van Calypso vastzit, geeft te kennen dat hij wil terugkeren naar zijn vrouw Penelope. De onsterfelijke nimf Calypso biedt hem aan dat zij hem tot een godgelijke zal maken, iemand die niet ouder wordt, nooit vermoeidheid zal kennen, nergens over hoeft te treuren en die altijd een kalm plezier zal mogen beleven (die dus geniet van een volstrekte onaangedaanheid en onbewogenheid). Maar Odysseus slaat het aanbod af. Hij geeft toe dat Penelope de vergelijking met Calypso niet kan doorstaan. Toch wil hij terug naar huis. Als een godheid hem onderweg met rampen zal bezoeken, zal hij die manmoedig doorstaan. Dat kan er nog wel bij.

Waarom moest Odysseus het aanbod afslaan?, vraagt Nussbaum zich vervolgens af. Het leven van de goden is op het eerste gezicht aantrekkelijk: ze kennen niet de vele beperkingen waaraan wij lijden. Maar het heeft ook iets onaantrekkelijks: wanneer we onsterfelijken zouden worden, zouden we ons geheel van onszelf vervreemden. Veel van de dingen die we nu kunnen doen, zouden ons worden ontnomen. Bijvoorbeeld atletiek: hoe moet je je een hardloopwedstrijd voorstellen tussen lieden die naar believen de vorm van hun lichaam kunnen veranderen en die zonder enige moeite van de ene plaats naar de andere gaan? Juist omdat we aan begrenzingen onderhevig 
zijn, heeft het zin dat we steeds weer proberen die grenzen te verschuiven. De goden hebben ook geen van onze motieven om van onze geliefden en kinderen te houden. Ze zijn niet bezorgd over hun toekomst, hebben er geen behoefte aan om door het krijgen van kinderen in zekere zin voort te leven, kennen niet het verlangen om wat zwak en kwetsbaar is te voeden en te beschermen. Het leven van goden is gewichtloos, amorf en zonder behoeften. In een haast wanhopige poging om aan menselijke passies deel te hebben, worden ze daarom soms verliefd op mensen. Dan kunnen ze zich zorgen maken over het menselijk lot en daarmee hun eigen lot verlichten. In het geval van Odysseus en Calypso is de liefde niet wederzijds. Wanneer haar dat duidelijk wordt, schikt Calypso zich, als een ware nimf, zonder morren in haar lot. Ze helpt Odysseus zelfs met het bouwen van het vlot waarmee hij het eiland Ogygia kan verlaten.

Van hieruit schetst Nussbaum enige karakteristieken van het menselijk leven. Het is typerend voor menselijk leven om de voorkeur te geven aan een leven met een telkens terugkerende honger en het stillen ervan, boven een leven zonder honger en zonder eten; om de voorkeur te geven aan seksuele begeerte die gepaard gaat met de bevrediging ervan, boven een leven zonder begeerte en zonder bevrediging. Zo ook wat de dood betreft: de wens onsterfelijk te zijn is een vreemde wens, omdat hij lijkt neer te komen op de wens om over te gaan naar een zo volstrekt andere manier van leven, met zozeer andere waarden en doelen, dat iemands identiteit daarin niet zonder meer bewaard kan blijven. Liever dus een sterfelijk leven dat zijn grenzen steeds tracht te overschrijden, dan een onsterfelijk leven zonder enige spanning.

Nussbaum opereert aldus met twee gedachten: de welbekende gedachte dat we onze eindigheid moeten zien te overschrijden, bijvoorbeeld door sporen na te laten, en de gedachte dat we haar juist moeten aanvaarden. Hoe gaan die twee gedachten met elkaar samen? Het is opvallend hoe weinig gedetailleerd de beschouwingen zijn die Nussbaum hieraan in haar publicaties wijdt. In steeds nieuwe bewoordingen benadrukt zij dat we de eindigheid tegelijk als een kwaad en als een goed moeten beschouwen. Hoe moet dat tegelijk? Daarover wil ik enige gedachten ontwikkelen.

Laten we ons leven indelen in drie delen: de fase van opbloei, de fase van aftakeling en een onduidelijke fase ertussenin. Als je nog in opbloei bent, doe je er goed aan je mogelijkheden aan te passen aan je wensen: je zult ervoor zorgen dat je ambities aan hun trekken komen. In die fase beschouw je de eindigheid als een kwaad: niet al je wensen zul je kunnen vervullen. Als je aan het aftakelen bent, doe je er goed aan je wensen aan te passen aan je mogelijkheden: wees tevreden met het kijken naar de bloemen in je tuin. In deze fase beschouw je het einde als iets dat bij het leven behoort, en dat je 
dus hebt te aanvaarden. Je kunt je dan zelfs troosten met de gedachte dat eeuwig voortleven niet aantrekkelijk is; tot welke verveling dat leidt, heeft Simone de Beauvoir in Tous les hommes sont mortels goed invoelbaar gemaakt; en ook bij Bernard Williams kun je, in zijn The Makropulos case: reflections on the tedium of immortality, daarover het een en ander lezen. Dat stelt de mens voor wat we een strategisch probleem kunnen noemen: wanneer dien je van de eerste levensfase, met de bijbehorende maxime, over te gaan naar de laatste? In die onduidelijke tussenfase verkeren mensen in dubio over de vraag of ze hun mogelijkheden moeten aanpassen aan hun wensen, dan wel hun wensen aan hun mogelijkheden.

Vaak verloopt ons leven echter niet zo ordelijk. Sommige mensen sterven te vroeg, nog voordat hun boek of hun kunstwerk af is. Met welke gedachte kunnen zij zich troosten? Niet met de gedachte dat het leven sowieso eindig is. Kijk naar het slotdeel van Prousts $A$ la recherche du temps perdu, geschreven door iemand die waarlijk sporen heeft nagelaten. De verteller zegt daar dat hij na lang dolen tot het inzicht is gekomen waarom het in zijn leven eigenlijk gaat: het schrijven van zijn boek. Het perspectief van dat boek geeft hem zo'n vreugde dat de gedachte aan de dood hem onverschillig laat. Maar op datzelfde moment komt de angst voor de dood opnieuw op, en wel in een 'beredeneerde' versie. Want hij kan een ongeluk krijgen, waardoor niet alleen de mijnwerker verdwijnt die al die kostbare mineralen kan opdelven, maar ook die mineralen zelf verloren gaan, want die zitten in zijn hoofd. Wanneer hij nu zou sterven, zou dat 'absurd' zijn, zegt de verteller ergens.

Andere mensen hebben hun uiterste best gedaan om hun mogelijkheden aan te passen aan hun wensen, maar hebben gefaald: hun boek is nooit verschenen. Met welke gedachte kunnen zij zich troosten? Moeten zij misschien zelfmoord plegen, omdat hun leven mislukt is? Er zijn weinig mensen die dat doen, om twee goede redenen. Ten eerste: het tijdstip waarop zij hun leven als mislukt hebben te beschouwen, is niet nauwkeurig bepaalbaar. Het kan zich over vele jaren uitstrekken: je omgeving heeft allang in de gaten dat er geen creatieve gedachte meer uit je voortkomt, maar jij denkt nog steeds dat je een God bent in het diepst van je gedachten. Ten tweede: als je na jaren doorkrijgt dat je niets te melden hebt, stop je gewoon met schrijven, niet vanuit de treurige gedachte dat het je aan creativiteit ontbreekt, maar omdat er echt niets te zeggen valt, niet door jezelf, maar ook niet door anderen, en ga je in plaats daarvan misschien in het bejaardentehuis een kaartje leggen.

Maar ook in die laatste fase gaat het er meestal niet ordelijk aan toe. Ook dan is het meestal zo dat in je eigen waarneming je dood weer te vroeg 
komt, want je had nog zo lang kunnen doorgaan met kaarten en kijken naar de bloemen. Slechts voor een enkeling, die te oud en te ziek is om nog ergens zin in te hebben, geldt dat hij oud en der dagen zat zijn hoofd te rusten legt. Alle anderen vinden dat ze te vroeg doodgaan en putten geen troost uit de gedachte dat het weinig aantrekkelijk is om, met Elina Makropulos, 342 jaren oud te worden en het eind dan nog niet in zicht te hebben. Als je vijftig jaar bent, is eenenvijftig jaar te vroeg; en als je vijfentachtig jaar bent, is zesentachtig jaar te vroeg. Slechts in uitzonderingsgevallen is het nu mooi geweest.

We staan dus voor het volgende probleem. Enerzijds moeten we erkennen dat mensen meestal goede redenen hebben om tegen ziekte en dood te vechten en zich dus niet neer te leggen bij de eindigheid van hun leven. Anderzijds moeten we erkennen dat er een tijdstip komt waarop je het hoofd te rusten moet leggen en het einde aanvaarden. Wanneer houd je echter op met vechten en probeer je tot aanvaarding te komen? $\mathrm{Bij}$ het beantwoorden van deze vraag biedt het algemene inzicht dat het leven grenzen en beperkingen heeft, geen enkel uitzicht. Vrijwel nooit zal iemand zeggen: 'Omdat het leven eindig is, zal ik vandaag maar stoppen met het nemen van mijn medicijnen.' Hij zegt dat alleen wanneer hij het meer dan moe is, namelijk op dat moment zelf. Wanneer wij nu in het algemeen met Nussbaum formuleren dat het leven een rijkdom aan mogelijkheden biedt doordat het grenzen en beperkingen kent, is dat een abstracte uitspraak, die geen gevolgen heeft voor ons handelen; in ons concrete handelen gaan we ervan uit dat het nog niet afgelopen is en stellen we ons teweer tegen het einde. Ons leven staat dan niet in het teken van de aanvaarding van de eindigheid, maar van de weigering om daarin te berusten.

Met andere woorden: de stelling dat we de begrensdheid van ons leven moeten overschrijden en de stelling dat we de begrensdheid van ons leven moeten aanvaarden, zijn asymmetrisch aan elkaar; ze spelen zich af op verschillende niveaus. Daarom raken ze elkaar niet: dat we onze grenzen willen overschrijden laat geheel onverlet dat we tegelijk kunnen inzien dat het hebben van grenzen een goede zaak is. Dat tweede ontneemt niets aan de motieven die aan het eerste ten grondslag liggen. Het is lastig om die twee asymmetrische gedachten in één betoog tegelijk tot hun recht te laten komen. Dat maakt het verhaal van Odysseus en Calypso zo fraai: Odysseus zou niet willen dat Penelope zo ongenaakbaar is als een godin met eeuwig gouden haren. Tegelijk ziet hij haar haren grijs worden, en betreurt hij dat.

Misschien hebben we hier te maken met een paradox die onoplosbaar is, en die je uiteindelijk niet filosofisch kunt benaderen, maar hoogstens literair. Zo'n paradox is inderdaad zichtbaar bij Achilles, de centrale figuur van de 
Ilias. In boek 9 vertelt hij dat de doodsdemonen hem voor de keus hebben gesteld om ofwel in de strijd voor Troje roem te verwerven, maar dit met een kort leven te bekopen, ofwel roemloos naar huis terug te keren; en Achilles heeft uiteraard gekozen voor het heroïsche pad, hetgeen aansluit bij Nussbaums transcendentie. Dezelfde Achilles die in boek 9 van de Ilias kiest voor de zelftranscendentie en het heroïsche bestaan, wordt in boek 24 geconfronteerd met Priamos, die komt vragen om het lijk van zijn door Achilles gedode zoon Hektor. Achilles en Priamos praten lang met elkaar, waarbij Achilles het heeft over zijn vader Peleus, die zijn zoon vroegtijdig zal zien sterven, nadat in de strijd die vanwege die trut van een Helena is losgebarsten velen zijn gedood en veel leed is veroorzaakt. Hier is niet de godgelijke held aan het woord die zijn eigen lot ondergeschikt maakt aan de missie die hij heeft, maar de sterveling die treurt over het droeve lot van hemzelf en van zijn medemensen. De hele Trojaanse oorlog wordt als zinloos afgedaan: die Helena was het niet waard dat Grieken en Trojanen elkaar jarenlang naar de keel vlogen. Hier staat de heroïsche Achilles, die de dood tart, naast de Achilles die de sterfelijkheid aanvaardt ondanks al haar treurigheid.

Ik vind de boodschap van de Ilias prachtig. We moeten niet, met Nussbaum, de schijn wekken dat we hier te maken hebben met een probleem dat met filosofische middelen opgehelderd en misschien zelfs opgelost kan worden, maar zijn eerder aangewezen op de beeldende kracht van de poëzie, die twee onderling onverenigbare gedachten toch samenbrengt.

\section{Medische schaarste en het menselijk tekort}

Welnu, die paradox rond het menselijk tekort speelt ons bij het medische handelen parten. Mede daardoor is het probleem van de medische schaarste principieel onoplosbaar. Met deze sombere, maar toch eigenlijk ook bevrijdende gedachte wil ik eindigen. 